\title{
Detecting tree water deficit by very low altitude remote sensing
}

\author{
Hilaire Martin (1), \\ Sylvain Labbé (2), \\ Patrick Baldet ${ }^{(1)}$, \\ Frédéric Archaux ${ }^{(1)}$, \\ Gwénaël Philippe ${ }^{(1)}$
}

\section{Introduction}

Important innovations in satellite sensors over the last decades have made available a great deal of information about landscape monitoring (Pettorelli et al. 2014). Using plant reflectance of both high and low wavelengths in infrared and red bandwidths, many vegetation indices have been created. Among these, the NDVI (Normalized Difference Vegetation Index) developed by (Rouse et al. 1973) is being widely used to study agricultural activities, biomass, plant productivity, chlorophyll concentrations and phenology. In forests, the NDVI has been used for about thirty years to assess fire risks (Gitas et al. 2014). In terms of stand productivity, NDVI values are strongly linked with leaf area index, which is a good indicator of plant biomass (Wang et al. 2005). Moreover, other studies have used the NDVI for tree species identification on monoculture plots (Carleer \& Wolff 2004). In addition, Camarero et al. (2010) used variations in NDVI to de-

(1) IRSTEA National Research Institute of Science and Technology for Environment and Agriculture, Domaine des Barres, F-45290 Nogent-sur-Vernisson (France); (2) IRSTEA, National Research Institute of Science and Technology for Environment and Agriculture, 361 rue J.F. Breton, BP 5095, F-34196 Montpellier Cedex 5 (France).

@ Hilaire Martin (hilaire.martin@irstea.fr)

Received: Apr 27, 2015 - Accepted: Nov 16, 2016

Citation: Martin $\mathrm{H}$, Labbé $\mathrm{S}$, Baldet $\mathrm{P}$, Archaux F, Philippe G (2017). Detecting tree water deficit by very low altitude remote sensing. iForest 10: 215-219. - doi: 10.3832/ifor1690-009 [online 2017-02-11]

Communicated by: Giorgio Matteucci

\begin{abstract}
In a context of climate change and expected increasing drought frequency, it is important to select tree species adapted to water deficit. Experimentation in tree nurseries makes it possible to control for various factors such as water supply. We analyzed the spectral responses for two genetic varieties of Douglas fir sapling exposed to different levels of water deficit. Our results show that the mean NDVI derived from remote sensing at very low altitudes clearly differentiated stress levels while genetic varieties were partially distinguished.
\end{abstract}

\section{Keywords: Very Low Altitude Remote Sensing, Water Deficit, Variety, Douglas} Fir

tect an increase in canopy cover preceding mast years for Quercus ilex. For drought monitoring, this vegetation index is of particular interest (Peng et al. 2012, Volcani et al. 2005). Drought conditions result in a reduction in soil water availability, and reduced levels of water in the soil layers alter both soil-root and leaf-atmosphere interfaces (Bréda et al. 2006). With global climate change, droughts are expected to become more frequent, and it is important to plant tree varieties selected for their resistance to dry conditions. Douglas fir (Pseudotsuga menziesii [Mirb.] Franco) was introduced in France for its exceptional stand productivity and the quality of its wood. However, this species comes from regions where annual rainfall exceeds 800 $\mathrm{mm}$ year ${ }^{-1}$, a level that is not always reached in the areas where the tree was introduced (Rozenberg et al. 2012). Particularly for saplings, water stress can cause mortality because the young tree's shallow roots are subjected to high temperatures in the topsoil (Bréda et al. 2000). In tree nurseries, we can experiment with drought effects on young trees by controlling the water supply. Coupled with the recently developed NDVI technology for crop monitoring (Lebourgeois et al. 2008, Meyer \& Camargo Neto 2008), we used modified commercial digital cameras and a mobile darkroom in order to extract NDVI at low cost. We studied the spectral response of two Douglas Fir varieties exposed to different stress levels.

\section{Material and methods}

Plant material and experimental design

The experiment took place on two-yearold Douglas fir saplings in a greenhouse during the 2013 growing season. Twentyfour boxes were planted with saplings following a two-way randomized block design crossing two genetic varieties ( $A$ and $B$ ) and six water stress levels, with one replication. Each box had been planted in 2012 on bare soil with 30 one-year-old trees. The rectangular boxes were $1.40 \mathrm{~m}$ by $1.10 \mathrm{~m}$ and $0.78 \mathrm{~m}$ deep (Fig. 1). The volume of soil available for roots in each box was $0.70 \mathrm{~m}^{3}$.

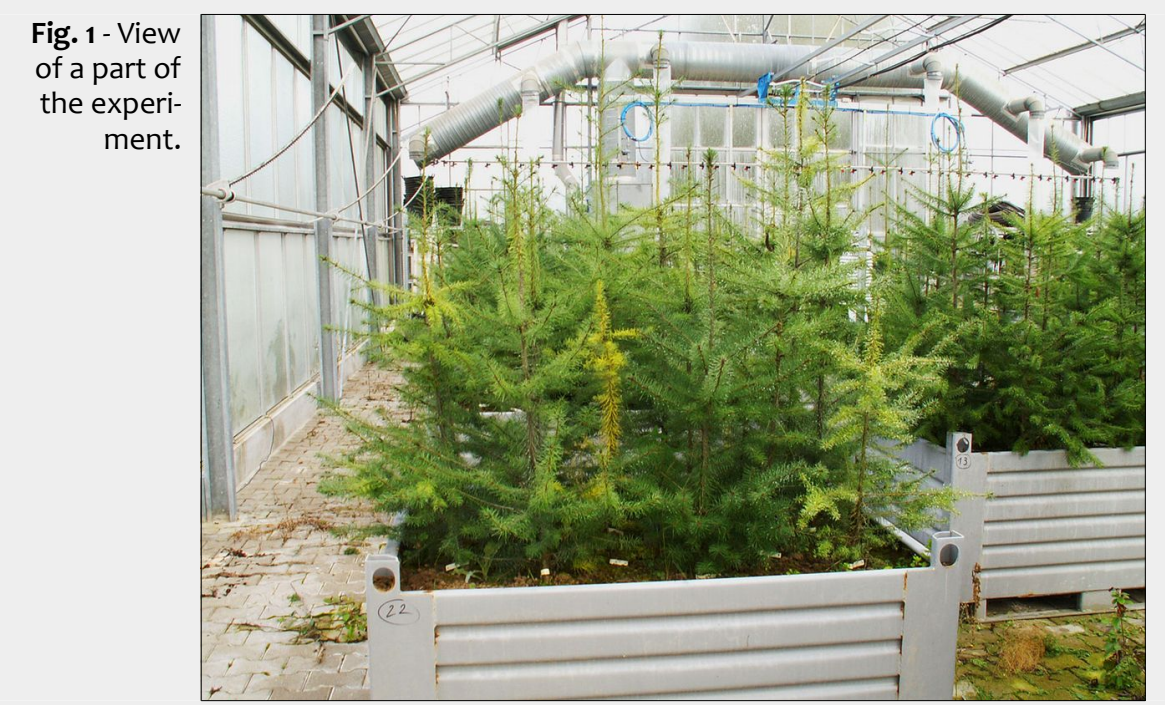




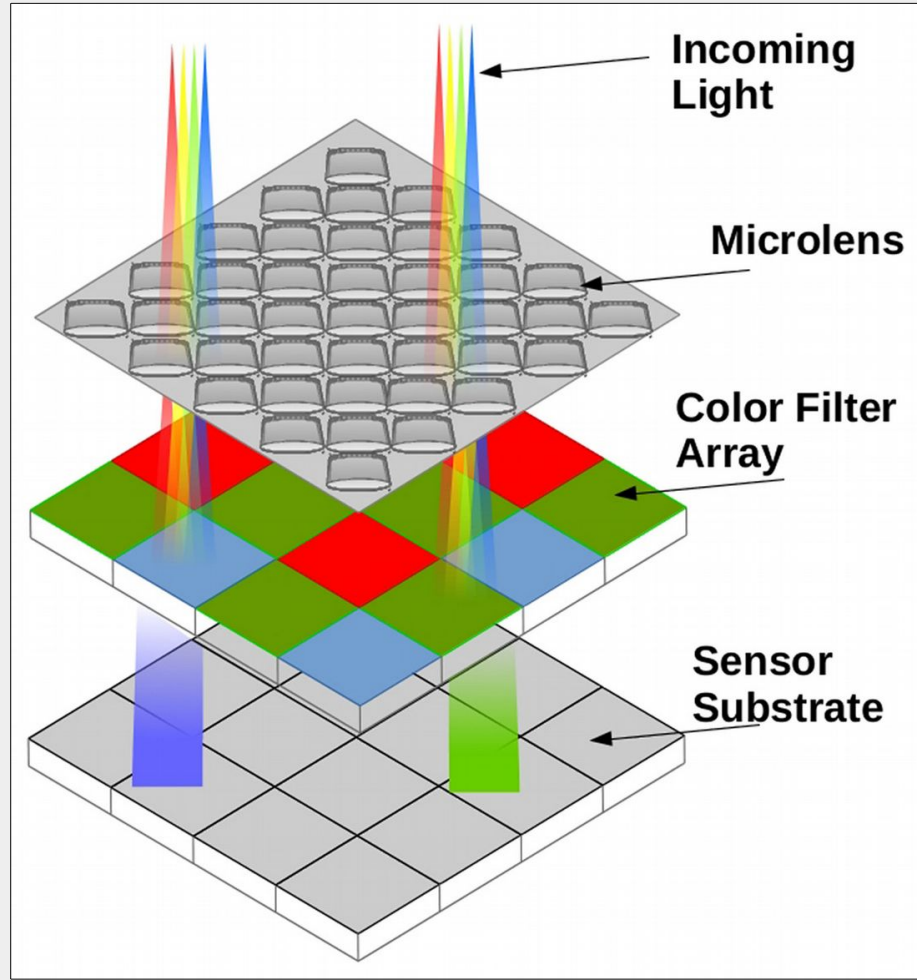

Fig. 2 - Color Filter Array.

Stress levels were measured by probes (TRIME-IPH) and 6 categories from 1 (wettest) to 6 (driest) were distinguished by Time-Domain Reflectometry (TDR) monitoring. Tab. 1 presents the percentage of soil water content for each stress level. Note that the intermediate level (Stress 3) was characterized by normal watering ( $15 \%$ water content) during the first phase of the experiment, then watering was completely suspended on August 6 $6^{\text {th }}, 2013$ in

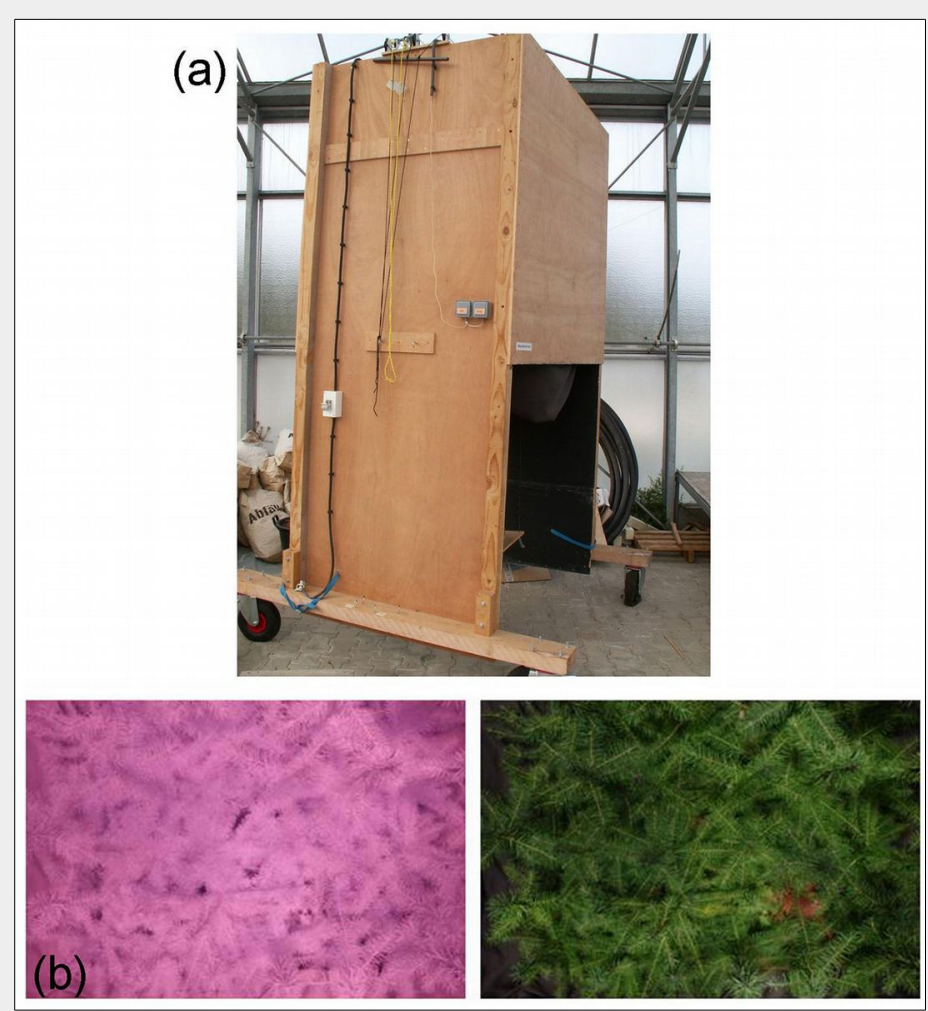

Tab. 1 - Percentage of soil water content by stress level.

\begin{tabular}{lc}
\hline Stress level & Soil Water (\%) \\
\hline Water deficit 1 & 19.6 \\
Water deficit 2 & 17.3 \\
Water deficit 3 & 15 \\
Water deficit 4 & 12.7 \\
Water deficit 5 & 10.4 \\
Water deficit 6 & 8.1 \\
\hline
\end{tabular}

trum but manufacturers affix a Color Filter Array (CFA), called "Bayer Matrix" (Fig. 2), in order to record only visible wavelengths (red, green and blue). When this filter is removed, commercial cameras become sensitive to infrared wavelengths (Rabatel et al. 2014). By photographing the same target with one modified and one nonmodified Canon ${ }^{\oplus}$ EOS 350D digital camera, we recorded both near infrared (NIR) and red (from RGB) bands that could be used to calculate the NDVI. A mobile darkroom was built in order to ensure identical photography conditions: target center points (tree box), light intensity and camera height (Fig. 3a, Fig. 3b). Cameras were attached to a sliding support on the top of the dark chamber in order to move alternatively each camera on a common image acquisition vertical axis ideally located in the center of the dark chamber roof. For light intensity we chose tungsten lights due to the major part of radiation emitted in the red and infrared wavelengths. The roof of the dark room was equipped with 6 tungsten lights (model Philips Aluline $111^{\circledR}$, $50 \mathrm{~W}, \mathrm{G} 53,12 \mathrm{~V} 8 \mathrm{D}, 1 \mathrm{CT}$ ) provided by batteries with accurate tension monitoring in order to guaranty color temperature of $3000 \mathrm{~K}$. Camera settings were kept unchanged throughout the experiment and images were recorded in RAW format with a constant focal length of $34 \mathrm{~mm}$ and the best resolution $(3456 \times 2304$ pixels $)$. We photographed the 24 boxes at three dates during the 2013 growing season: August $30^{\text {th }}$, October $4-5^{\text {th }}$, November $4-5^{\text {th }}$.

\section{Image treatment}

We processed the images with the ArcGIS $^{\oplus}$ software version 10.2. In lack of spectral calibration of cameras, we divided red and near infrared bands with a gray target (more visible in infrared spectrum) of constant reflectance in order to overcome different lighting effects related to bandwidth (Fig. 4). A panel was painted with three layers of gray matt acrylic paint (AFNOR NF T 36-005) to obtain a homogeneous reference surface with low reflectance. An image of the gray target was acquired with the modified and non-modified cameras in order to quantify lighting heterogeneity, reflectance from lateral walls and other uncontrolled effects. Due to different wavelengths in infrared and visible bandwidths, settings differ from cameras (Tab. 2). Thereafter we kept same 


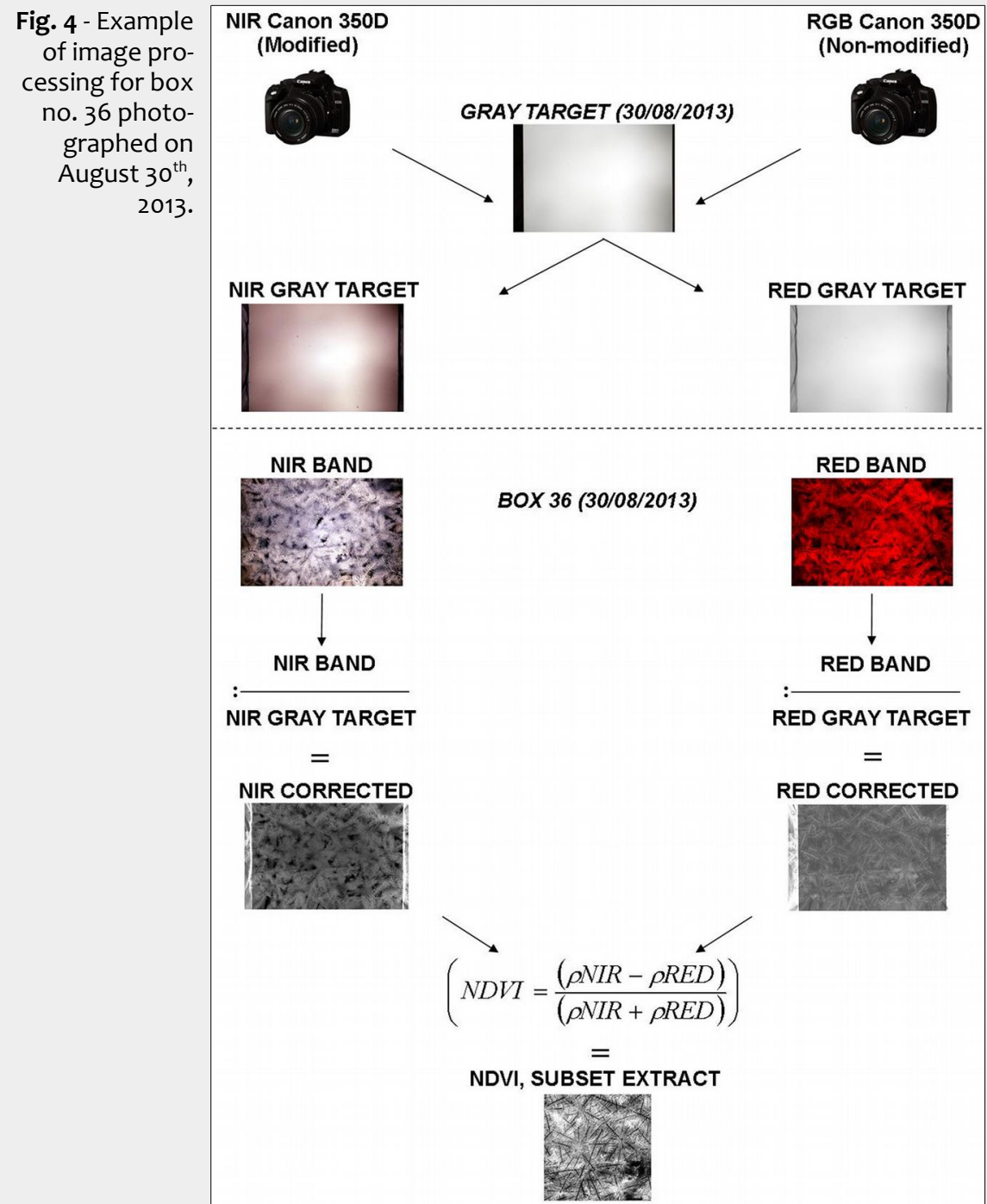

settings of cameras for the plant material image acquisition. Only one picture of red and infrared spectrum was used as reference for correcting all pictures acquired on plant material.
We performed our analysis on a square mask centered on the middle of the image to avoid vignette effects $(500 \times 500$ pixels $)$. The NDVI of each box was calculated by automatic image processing for the three
Tab. 2 - Canon $^{\circledast}$ EOS 350D Camera settings.

\begin{tabular}{lccc}
\hline Camera & $\begin{array}{c}\text { Shutter } \\
\text { speed }\end{array}$ & $\begin{array}{c}\text { Sensiti- } \\
\text { vity }\end{array}$ & Aperture \\
\hline NIR & 0.4 & 100 & 22.0 \\
$\begin{array}{l}\text { NIR GRAY } \\
\text { TARGET }\end{array}$ & 0.4 & 100 & 22.0 \\
RGB & 0.5 & 100 & 11.0 \\
$\begin{array}{l}\text { RGB GRAY } \\
\text { TARGET }\end{array}$ & 0.5 & 100 & 11.0 \\
\hline
\end{tabular}

dates as follows (eqn. 1):

$$
N D V I=\frac{\rho \mathrm{NIR}-\rho \mathrm{RED}}{\rho \mathrm{NIR}+\rho \mathrm{RED}}
$$

where $\rho$ is the reflectance value in spectral bands.

\section{Statistical analyses}

We used linear mixed effects models with gaussian error distribution to analyse the effects of stress (6 levels) and varieties (2 levels) and their interaction on the mean NDVI (calculated on $25 \times 10^{4}$ pixels per box and per date). A random "box" effect was added on the intercept to take into account a potential effect of replication (there were two boxes for a given variety and a level of stress, 12 replications in total). We used an analysis of variance (ANOVA, $a=0.05$ ) to assess the effects of treatments (stress $\times$ variety) on the response variable. All analyses were performed in $\mathrm{R}$ version 3.1.0 ( $\mathrm{R}$ Development Core Team 2014), using the library "nlme".

\section{Results}

\section{Stress effect}

In general, $N D V I_{\text {mean }}$ decreased with stress intensity during the growing season (Fig. 5a, Fig. 5b, Fig. 5c). Specifically, starting in August, $N D V I_{\text {mean }}$ decreased almost linearly from stress level 1 (well watered) to 5 (almost never watered). Fig. $5 \mathrm{C}$ shows the (a)

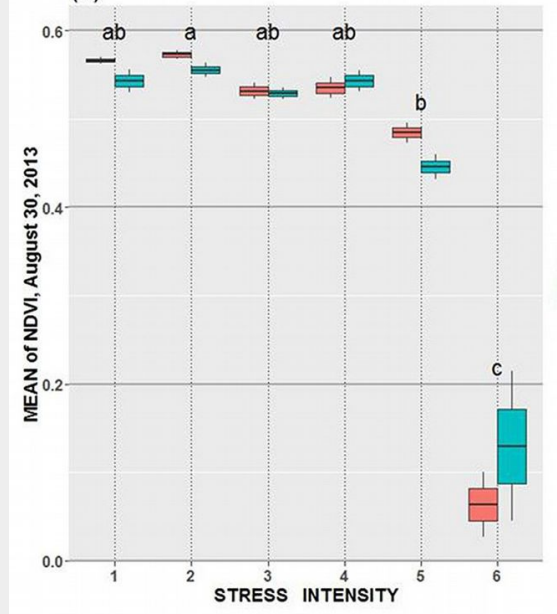

(b)

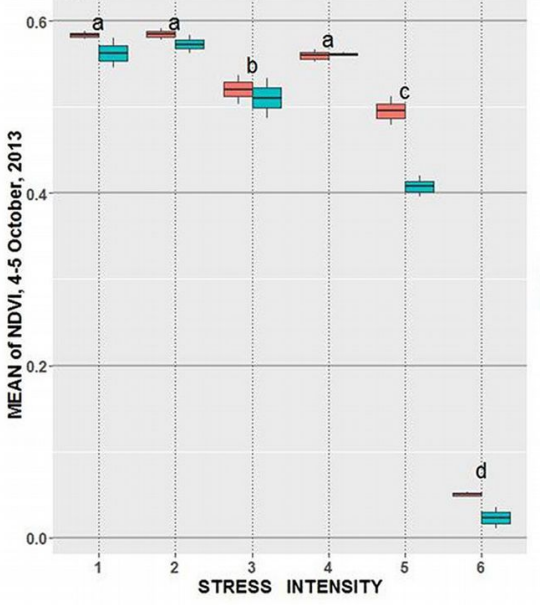

(c)

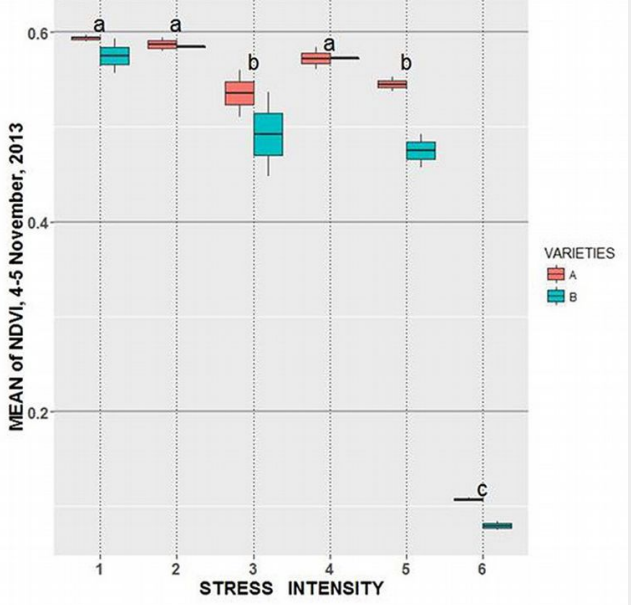

Fig. 5 - Mean NDVI at different dates. Different letters indicate significant differences in stress intensity (Tukey's HSD test, with $P<$ $0.05)$. 
Tab. 3 - ANOVA results of the effects of stress and origin on mean tree NDVI per box for three dates (calculated on $25 \times 10^{4}$ pixels). (df): degrees of freedom; $(*): p \leq 0.05$; $(* *): p \leq 0.01 ;(* * *): p \leq 0.001$

\begin{tabular}{llccrl}
\hline Date & Variable & df & $\begin{array}{c}\text { Mean } \\
\text { Square }\end{array}$ & F value & Pr $>(\mathrm{F})$ \\
\hline NDVI & STRESS & 5 & 0.65 & 82.02 & $7.45 \mathrm{e}-09^{* * *}$ \\
30 Aug 2013 & VARIETIES & 1 & 0.00 & 0.00 & 0.93 \\
& ST $\times$ VA & 5 & 0.00 & 0.84 & 0.54 \\
NDVI & STRESS & 5 & 0.17 & 545.14 & $1.03 \mathrm{e}-13^{* * *}$ \\
$4-5$ Oct 2013 & VARIETIES & 1 & 0.00 & 12.65 & $0.003^{* *}$ \\
& ST $\times$ VA & 5 & 0.00 & 3.15 & $0.04^{*}$ \\
NDVI & STRESS & 5 & 0.14 & 251.23 & $1.04 \mathrm{e}-11^{* * *}$ \\
$4-5$ Nov 2013 & VARIETIES & 1 & 0.00 & 7.57 & $0.01^{*}$ \\
& ST $\times$ VA & 5 & 0.00 & 1.22 & 0.35 \\
\hline
\end{tabular}

lowest $N D V I_{\text {mean }}$ values for stress level 6 at around 8 percent soil water content. By the end of the experiment, all the plants in this category had died. For the second period (Fig. 5b), when watering was suddenly stopped in August, NDVI mean decreased for stress 3. This trend was more pronounced at the end of the growing season (Fig. 5C). Throughout the experiment, stress effect levels were significantly different (Tab. 3).

\section{Variety effect}

During the growing season, differences between varieties were slightly statistically significant starting since October. There was only one significant interaction between stress level and genetic variety in the second period (Tab. 3).

\section{Discussion}

In this experiment, we studied the spectral response of two Douglas Fir varieties exposed to different water stress levels during the 2013 growing season. To be cost effective, we adapted a method used in crop studies and used a modified digital camera and a non-modified digital camera (Rabatel et al. 2014, Lebourgeois et al. 2008, Jensen et al. 2007) and a mobile darkroom. This technology has also been used for forest monitoring with Unmanned Aerial Vehicles (Lisein et al. 2014).The results in Tab. 3, Fig. 5a, Fig. 5b and Fig. 5c are promising for very low altitude NDVI in water deficit monitoring. Because water deficit events strongly impact young tree roots (Bréda et al. 2000), it is important to test the most suitable tree species in a global climate change context. We were not able to provide results on genetic variety effects in our experiment due to methodological limitations (not enough replications) and similar spectral responses by the two genetic varieties. From a forestry point of view, these results are insufficient. Indeed, an experiment on only one growing season cannot predict stress behavior over the life of a stand. We should measure dendrometric variables for at least two successive years, as suggested in Becker's work (Becker 1974), in order to test correlations between tree sizes and spectral responses.

\section{Conclusions}

Very low altitude remote sensing could have a positive impact in tree nurseries. Further research may focus on testing photography with direct solar light in order to avoid the use a mobile darkroom. Other vegetation indices, including simpler ones based only on RGB bands, could also be tested, following the suggestion for crop monitoring by Meyer \& Camargo Neto (2008).

\section{Acknowledgements}

We thank Anne Villemey, Yoan Paillet and Emmanuel Cornieux for their constructive comments and Stéphane Matz, Vincent Bourlon, Pascal Croizet, Franck Stocchero, Aurélien Brochet and Cécile Joyeau for constructing the mobile darkroom and for image acquisition.

\section{Authors' Contributions}

S.L., P.B., G.P., conceived and designed the experiment, H.M., F.A., analyzed data, and all authors equally contributed in writing the paper.

\section{References}

Becker M (1974). Étude expérimentale de la transpiration et du développement de jeunes Douglas en fonction de l'alimentation en eau ment of young Douglas fir controled by water supply]. Annals of Forest Science 31: 997-109. [in French] [online] URL: http://www.afsjournal.org/articles/forest/pdf/1974/02/AFS 000 3-4312_1974_31_2_ART0003.pdf

Bréda N, Granier A, Aussenac G (2000). Evolutions possibles des contraintes climatiques et conséquences pour la croissance des arbres [Possible changes in climatic constraints and consequences for tree growth]. Revue forestière Française (numéro spécial) 52: 73-90. [in French] - doi: 10.4267/2042/5407

Bréda N, Huc R, Granier A, Dreyer E (2006). Temperate forest trees and stands under severe drought: a review of ecophysiological responses, adaptation processes and long-term consequences. Annals of Forest Science 63: 625-644. - doi: 10.1051/forest:2006042

Camarero JJ, Albuixech J, López-Lozano R, Casterad MC, Montserrat-Martí G (2010). An increase in canopy cover leads to masting in [Experimental study of sweating and develop-
Quercus ilex. Trees 24: 909-918. - doi: 10.1007/ s00468-010-0462-5

Carleer A, Wolff E (2004). Exploitation of very hign resolution satellite data for tree species identification. American Society for Photogrammetry and Remote Sensing 70 (1): 135-140. - doi: 10.14358/PERS.70.1.135

Gitas IZ, San-Miguel-Ayanz J, Chuvieco E, Camia A (2014). Advances in remote sensing and GIS applications in support of forest fire management. International Journal of Wildland Fire 23: 603-605. - doi: 10.1071/WF14117

Jensen T, Apan A, Young F, Zeller L (2007). Detecting the attributes of a wheat crop using digital imagery acquired from a low-altitude platform. Computers and Electronics in Agriculture 59: 66-77. - doi: 10.1016/j.compag.2007.05. 004

Lebourgeois V, Bégué A, Labbé S, Mallavan B, Prévot $L$, Roux $B$ (2008). Can commercial digital cameras be used as multispectral sensors? A crop monitoring test. Sensors 8: 7300-7322. doi: $10.3390 / \mathrm{s} 8117300$

Lisein J, Bonnet S, Lejeune P, Pierrot-Deseiligny M (2014). Modélisation de la canopée forestière par photogrammétrie depuis les images acquises par drone [Modeling forest canopy by photogrammetry from images acquired by drone]. Revue Française de Photogrammétrie et de Télédétection 206: 45-54. [in French] [online] URL: http://orbi.ulg.ac.be/handle/2268/17 1270

Meyer GE, Camargo Neto J (2008). Verification of color vegetation indices for automated crop imaging applications. Computers and Electronics in Agriculture 63: 282-293. - doi: 10.1016/j. compag.2008.03.009

Peng J, Dong W, Yuan W, Zhang Y (2012). Responses of grassland and forest to temperature and precipitation changes in northeast China. Advances in Atmospheric sciences 29 (5): 1063-1077. - doi: 10.1007/s00376-012-1172-2 Pettorelli N, Laurance WF, O'Brien TG, Wegmann M, Nagendra H, Turner W (2014). Satellite remote sensing for applied ecologist: opportunities and challenges. Journal of Applied Ecology 51: 839-848. - doi: 10.1111/1365-2664.12261

R Development Core Team (2014). R: a language and environment for statistical computing. $R$ Foundation for Statistical Computing, Vienna. [online] URL: http://www.R-project.org/ Rabatel G, Gorreta N, Labbé S (2014). Getting simultaneous red and near infrared bands from a single digital camera for plant monitoring applications: Theoretical and practical study. Biosystems Engineering 117 (1): 2-14. - doi: 10.1016/j.biosystemseng.2013.06.008

Rouse J, Haas RH, Schell JA, Deering DW (1973). Monitoring vegetation systems in the great plains with ERTS. In: Proceeding of the " 3 rd ETRS Symposium”, NASA SP-351 1, US Government Printing Office, Washington, DC, USA, pp. 309-317.

Rozenberg P, Sergent A-S, Dalla-Salda G, Martinez-Meier A, Marin S, Ruiz-Diaz M, Bastien J-C, Sanchez L, Bréda N (2012). Analyse rétrospective de l'adaptation à la sécheresse chez le douglas [Retrospective analysis of drought adaptation in Douglas fir]. Schweiz Z Forstwes 163 (3): 88-95. [in French] - doi: 10.3188/szf.2012.0088 Volcani A, Karnieli A, Svoray T (2005). The use of 
Detecting tree water deficit by very low altitude remote sensing

remote sensing and GIS for spatio-temporal analysis of the physiological state of semi-arid forest with respect to drought years. Forest Ecology and Management 215: 239-250. - doi: 10.1016/j.foreco.2005.05.063

Wang Q, Tenhunen J, Granier A (2005). On the relationship of NDVI with leaf area index in a deciduous forest site. Remote sensing of Envi- ronment 94 (2): 244-255. - doi: 10.1016/j.rse.20 04.10 .006 